\title{
A REFORMA DA EDUCAÇÃO SUPERIOR NO BRASIL: DA HERANÇA NEOLIBERAL DE FHC AO LEGADO DE LULA
}

The reform of college education in Brazil: the legacy of neoliberal FHC to Lula's legacy

La reforma de la educación superior en Brasil: el legado neoliberal de FHC con el legado de Lula

\section{Ione Cristina Vieira Nunes ${ }^{*}$, Lucelma Silva Braga ${ }^{2}$}

${ }^{1}$ Instituto Federal de Educação Ciência e Tecnologia do Tocantins - IFTO, Paraíso do Tocantins, Brasil.

${ }^{2}$ Universidade Federal do Maranhão, Campus IV- UFMA, São Luis, Brasil.

*Correspondência: Rua Castro Alves, 1282, Jardim Paulista, Paraíso do Tocantins, Tocantins, Brasil.

CEP:77.600-000.e-mail: ione.nunes@ifto.edu.br

Artigo recebido em 04/05/2016. Aprovado em 19/09/2016. Publicado em 25/10/2016.

\section{RESUMO}

O presente artigo estuda as políticas para a reforma da educação superior brasileira implementada no governo Fernando Henrique Cardoso (FHC) e aprofundada no governo Lula, promovida de acordo com as diretrizes políticas do Banco Mundial. Trata-se de um estudo bibliográfico, baseado nas principais discussões teóricas sobre a temática e na análise das principais políticas desses dois governos, e a anuência às diretrizes do Banco Mundial. Aproximando-se da realidade objetiva mais recente, lança-se mão dos dados disponíveis nos órgãos oficiais como o Ministério da Educação (MEC), Instituto Nacional de Estudos e Pesquisas Educacionais Anísio Teixeira (INEP) e Banco Mundial. Evidencia-se o processo de mercantilização da educação superior, operado pelos governos FHC e Lula, estruturando um tipo de universidade adequada ao capital, nessa etapa de sua mundialização.

Palavras-chave: Banco Mundial. Educação Superior. Reforma.

\begin{abstract}
This article studies the policies to reform the Brazilian higher education implemented in the government of Fernando Henrique Cardoso (FHC) and depth in the Lula government, promoted in accordance with the policy guidelines of the World Bank. This is a bibliographic study based on major theoretical discussions on the subject and analysis of key policies of the two governments, and the agreement to the World Bank guidelines. Approaching the latest objective reality, launches hand of data available in the official bodies such as the Ministry of Education (MEC), National Institute of Educational Studies Teixeira (INEP) and the World Bank. This study highlights the commodification of higher education operated by FHC and Lula, structuring a suitable type of university capital, at this stage of its globalization.
\end{abstract}

Keywords: World Bank. College Education. Reform.

\section{RESUMEN}

Este artículo estudia las políticas de reforma de la educación superior brasileña implementado en el gobierno de Fernando Henrique Cardoso (FHC) y la profundidad en el gobierno de Lula, promovido de acuerdo con las directrices de la política del Banco Mundial. Se trata de un estudio bibliográfico sobre la base de las principales 
discusiones teóricas sobre el tema y el análisis de las políticas clave de los dos gobiernos, y el acuerdo con las directrices del Banco Mundial. Al acercarse a la última realidad objetiva, lanza la mano de los datos disponibles en los organismos oficiales como el Ministerio de Educación (MEC), Instituto Nacional de Estudios para la Educación Teixeira (INEP) y el Banco Mundial. Este estudio pone de relieve la mercantilización de la educación superior operado por FHC y Lula, la estructuración de un tipo adecuado de capital universitaria, en esta etapa de su globalización.

Descriptores: Banco Mundial. Educación universitaria. Reforma.

\section{INTRODUÇÃO}

A universidade tem perdido seu espaço de discussão crítica, de sistematização e difusão da ciência e da cultura elaborada, para responder aos interesses capitalistas, a gosto do neoprodutivismo, via empresariamento do ensino, respondendo aos apelos mercadológicos da conjuntura mundial.

Tal processo faz parte de um conjunto de ajustes arquitetados mundialmente para a manutenção e o desenvolvimento da hegemonia das classes dominantes, que tendo a ação efetiva das agências financeiras internacionais e a adesão ativa dos governos nacionais, atribuem um novo papel à universidade.

Nesse contexto, o presente texto se propõe a estudar a reforma da educação superior no Brasil, iniciada no governo Fernando Henrique Cardoso (FHC) e intensificada no governo Luís Inácio Lula da Silva (Lula), operada de acordo com as diretrizes políticas do Banco Mundial, dentro da conjuntura internacional.

Trata-se de um estudo bibliográfico, baseado nas principais discussões teóricas sobre a temática e na análise das principais políticas educacionais implementadas nesses dois governos, e a anuência às diretrizes do Banco Mundial. Aproximando-se da realidade objetiva mais recente, lançando mão dos dados disponíveis nos órgãos oficiais como o Ministério da Educação (MEC), Instituto Nacional de
Estudos e Pesquisas Educacionais Anísio Teixeira (INEP) e o próprio organismo internacional.

Estuda-se o histórico de intervenções que o Banco Mundial vem exercendo na educação brasileira, com ênfase nas reformulações para a educação superior; enfatiza-se a herança neoliberal do governo FHC a partir do conjunto de reformulações implementadas na educação brasileira; por fim, discute-se a reforma da educação superior intensificada no governo Lula, principalmente no que diz respeito à expansão do ensino privado e dos mecanismos que potencializaram a incorporação da lógica mercantil na educação pública.

\section{BANCO MUNDIAL E EDUCAÇÃO: UMA ESTRATÉGIA CAPITALISTA}

O Banco Mundial foi fundado em 1944, na Conferência Monetária e Financeira das Nações Unidas em Bretton Woods, no Estado de New Hampshire, Estados Unidos, realizada com o objetivo de traçar estratégias que pudessem colaborar para a reconstrução dos países europeus no pós-guerra, com vistas a garantir sua estabilidade e crescimento econômico (SILVA, 2002).

O objetivo inicial de recuperar os países devastados pelos efeitos da Segunda Guerra Mundial, aos poucos foi sendo deixado de lado e o Banco Mundial tornou-se uma importante fonte de créditos financeiros para os países periféricos e principal levantador de recursos no mercado mundial de 
capitais. Assumindo, portanto, uma posição estratégica no mundo capitalista, somado a outros organismos internacionais que desde então atuam em diferentes frentes, tais como o Fundo Monetário Internacional (FMI), Organização Mundial do Comércio (OMC), Organização das Nações Unidas para a Educação, a Ciência e a Cultura (UNESCO), entre outros.

Conforme análise de Silva (2002) foi na gestão de McNamara (1968-1981) que a educação ganhou importância nas proposições do Banco Mundial. Sendo enfatizada como uma indústria que necessitaria passar por uma revolução no âmbito tecnológico, passando-se a investir no que se chamou de expansão horizontal da educação, isto é, expansão da educação como necessidade de todos e essencial para o desenvolvimento econômico. Entretanto, de qualidade apenas para uma minoria, caracterizando assim um processo de dualismo educacional, marcante em toda a história da educação brasileira.

Na década de 1980, uma questão pontual para a atuação do Banco Mundial foi a crise de endividamento externo dos países latino-americanos, fato este que o permitiu, juntamente com o FMI, assumir a tarefa de formular políticas para a educação, passando a interferir, por meio de políticas setoriais, nos rumos da educação e sua subordinação aos procedimentos econômicos (SILVA, 2002).

A importância política do Banco Mundial junto ao setor educacional veio crescer mais expressivamente após sua importante atuação na Conferência Mundial de Educação para Todos, em 1990, resultando em propostas que fundamentariam as políticas educacionais dos países participantes.

A Conferência de Nova Delhi, realizada em 1993, deu continuidade ao debate sobre a proposta internacional iniciada em 1990, desta vez congregando os países mais populosos do mundo.
Foram identificadas as principais dificuldades enfrentadas por países de grande população e sugeridas prioridades e estratégias para planos nacionais de ação, fundamentados nos compromissos expressos na declaração resultante dessa Conferência, que aponta possíveis áreas de cooperação em nível internacional (BRASIL, 1993).

A realização destas conferências, e os documentos delas resultantes, foi uma forma estratégica de propagar mais rapidamente essas proposições e fazer com que elas se tornassem concretas nos países periféricos e garantissem o mínimo de educação necessária à produtividade.

Sob o manto de combate à pobreza inscrevese, portanto, a reforma neoliberal da política educacional, através da expansão de políticas mais convenientes aos interesses do capital. Restringindo à educação o papel de reproduzir a força de trabalho para o capital, de (con) formar ideologicamente de acordo com os seus interesses e servir como segmento do mercado a ser explorado comercialmente pelo setor privado.

Nesse contexto, a expansão da educação superior também adquire importância estratégica nas políticas neoliberais difundidas pelo Banco Mundial, que, junto com outros organismos internacionais e sob o discurso de democratização do acesso, intensifica a privatização do ensino, em dois pontos centrais: a expansão das instituições privadas e privatização interna das universidades públicas.

No documento Educação Superior: lições derivadas da experiência, o Banco Mundial (1994) traz uma lista que ele chama de "opções de políticas" para reforçar a contribuição da educação superior para o desenvolvimento econômico e social e lança algumas estratégias para reformá-la: a diversificação das instituições de ensino superior e dos cursos e das fontes de financiamento para o ensino público; 
redefinição do papel do governo no ensino superior, estimulando a privatização; adoção de políticas de qualidade e equidade no ensino superior, estas por sua vez criadas a partir do eficiente atendimento aos setores privados. Dar-se ênfase ao desenvolvimento de instituições não universitárias e de estabelecimentos privados como forma de atender as demandas da sociedade por educação, adequando-a as necessidades do mercado de trabalho.

Nesse contexto, as instituições privadas seriam uma maneira de expandir o direito à educação, sem custo adicional para o Estado. As reformas nas fontes de financiamento para as universidades públicas visavam: a mobilização de mais financiamento privado para o ensino superior; apoio aos estudantes carentes; melhoria na alocação e uso de recursos fiscais dentro das instituições. O papel do governo seria o de fornecer ambiente propício para as instituições públicas e privadas. A aplicação de tais reformas dependeria, portanto, do estabelecimento de um quadro político coerente, com mais incentivos de apoio à implementação de políticas orientadas para o mercado e mais autonomia na gestão das instituições públicas (BANCO MUNDIAL, 1994).

Sob essa perspectiva, aprofunda-se a mercantilização da educação superior que a ser vista como um serviço/treinamento oferecido a baixo custo, que tornaria os países mais competitivos no mercado global, sendo responsabilidade destes chegar a esse patamar.

\section{No Relatório sobre o Desenvolvimento} Mundial, o Banco Mundial (1997) impulsiona a privatização dos serviços públicos, através do reordenamento do papel do Estado nos países periféricos, tornando-o mais confiável e eficiente para o desenvolvimento dos mesmos.

Segundo Lima (2011) a lógica que impera nesta proposta é a do Estado mínimo e do mercado como controlador das relações sociais, afinal o Estado seria sim fundamental para o desenvolvimento econômico e social, todavia não como responsável direto, mas enquanto um fomentador desse processo de crescimento.

O papel do Estado seria de atuar:

\begin{abstract}
a) em ações que promovam a segurança pública (do combate à violência às parcerias com os empresários e trabalhadores no financiamento do sistema de seguridade social); b) na elaboração de uma regulamentação eficaz que aproveite as "forças do mercado" em benefício dos "bens públicos", estimulando as parcerias público-privadas; c) no incentivo à política industrial, inclusive com subvenções para o setor privado; d) na gestão eficaz da privatização das empresas estatais; e) no estímulo a maior "competência" no interior da administração pública, através de um sistema de contratação por mérito e de avaliação por produtividade e f) na formulação de políticas que viabilizassem a participação dos empresários, dos sindicatos e dos usuários na supervisão dos serviços da administração pública (BANCO MUNDIAL, 1997, in LIMA, 2011, p. 88).
\end{abstract}

Isso nos permite um parêntese para retomar a política de ajuste educacional promovida a partir do Consenso de Washington ${ }^{1}$, que marcou o início de um período bastante produtivo para o capital no que diz respeito ao desenvolvimento estratégico da educação para o desenvolvimento econômico.

A perspectiva defendida pelo neoliberalismo era de que a crise enfrentada pelos sistemas educacionais era de eficiência, eficácia e produtividade, fruto da incapacidade do Estado para

${ }^{1} \mathrm{O}$ Consenso de Washington caracteriza-se como um conjunto de medidas políticas, formulado em 1989 para atender às necessidades do capital internacional em processo de globalização. Seus eixos principais são: equilíbrio orçamentário, mediante, sobretudo, a redução dos gastos públicos; abertura comercial; liberalização financeira; desregulamentação dos mercados domésticos, pela diminuição da intervenção estatal; privatização das empresas e dos serviços públicos (SOARES, 1996). 
administrar as políticas sociais, sendo necessário reordená-lo.

Através da redefinição do papel do Estado acentua-se o processo de privatização dos serviços públicos, por meio do qual a educação, em especial a superior, tem sido progressivamente transferida do âmbito político para o âmbito do econômico, passando de um direito social para um bem de consumo individual, como uma espécie de produto a ser consumido no diversificado mercado educacional.

Sendo a educação tomada como uma mercadoria, alicerçada pelos princípios do mercado e, por sua vez, reduzida à sua função econômica, a retórica neoliberal passa a pensar e a projetar políticas educacionais com a aparência de inovadoras e essenciais, mas que na verdade expressam os interesses do capital, especialmente no contexto da profissionalização, ligada à formação de competências e habilidades, com políticas centradas no treinamento de indivíduos a serviço do mercado.

O neoliberalismo procura por meio de suas políticas e ideologias ressignificar o contexto pedagógico, pregando uma individualização alienante e cada vez mais desumanizada, pautada em princípios meritocráticos.

Nessa perspectiva, segundo Martins (2004) as políticas educacionais embalam um "ingênuo sonho", de um sistema educacional comprometido com o sucesso profissional dos indivíduos, que reduz a educação à formação de competências e empobrece os fins educacionais, transformando-o sem meios para a adaptação, de maneira passiva, dos indivíduos às exigências capitalistas.

Por meio do Documento estratégico do Banco Mundial: a educação na América Latina e Caribe, divulgado em 1999, reforça-se a tática de usar educação no combate à pobreza, articulada à ampliação do setor privado. Intensifica-se o empresariamento dos serviços educacionais, sob a perspectiva capitalista de educação como ferramenta de preparação da força de trabalho para o mercado e de domínio ideológico burguês.

Desse modo, o Banco Mundial relaciona a educação ao crescimento econômico e ao desenvolvimento social de maneira a aumentar a capacidade produtiva das sociedades e contribuir para a redução da pobreza, acrescentando valor e eficiência ao trabalho dos pobres.

Segundo Lima (2011) esse processo de empresariamento da educação parte de três importantes elementos: a globalização dos sistemas de educação, para estabelecer um arcabouço ideológico e político, legitimando a lógica dominante; a implantação de universidades corporativas; e o estímulo ao investimento na educação à distância.

Através da proposta expressa no documento Construir sociedades de conhecimento: novos desafios para a educação terciária, publicado em 2002 pelo Banco Mundial, a mercantilização da educação superior torna-se ainda mais intensa, deslocando a concepção de educação superior para educação terciária.

A educação terciária é enfatizada pelo Banco Mundial (2002) no contexto de algumas tendências: as novas demandas do mercado de trabalho e das novas tecnologias; a competitividade entre as universidades privadas e as chamadas emergentes, tida como benéfica, na medida em que favorece mais inovação e eficiência; e o incentivo a um mercado internacional de educação.

Esse processo de deslocamento da educação superior para educação terciária está ligado à concepção de sociedade do conhecimento ${ }^{2}$, uma

\footnotetext{
${ }^{2}$ Segundo Saviani (2010), seria mais adequado chamá-la de sociedade da informação, pois sociedade do conhecimento pressupõe as bases, os fundamentos do conhecimento, e
} 
questão-chave destacada no documento, no qual educação seria o primeiro fator a ser considerado na produção da economia mundial.

O aprofundamento da diversificação das instituições de ensino superior e dos cursos e das fontes de financiamento é uma das prioridades do Banco Mundial (2002, p.27).

\begin{abstract}
Crescente diversificação institucional (crescimento de instituições não universitárias e privadas) para ampliar a cobertura de forma financeiramente viável e estabelecer um quadro de aprendizagem ao longo da vida, com vários pontos de entrada e vários caminhos.
\end{abstract}

É nesse contexto de diversificação que se inicia uma intensa reestruturação da educação superior no Brasil, que tem suas políticas adequadas ao receituário neoliberal e contrário do que tem se pensado predominantemente, isso vem acontecendo mediante o consentimento e a anuência dos dirigentes locais. Por meio de uma convergência de opiniões e interesses entre governo, elites nacionais e Banco Mundial.

A aprovação da Lei 9.394/96, no governo FHC, constitui-se uma das principais mudanças no arcabouço legal brasileiro, como veremos adiante, que demonstram a anuência dos governos nacionais às diretrizes internacionais para a educação superior, criando condições para a diversificação das instituições e das fontes de financiamento.

\section{A HERANÇA NEOLIBERAL DE FHC}

O governo FHC teve suas políticas orientadas pela cartilha neoliberal, em especial dos postulados do Consenso de Washington, voltados para as políticas de mercado. Associado e subordinado aos organismos internacionais, FHC efetivou no Brasil

isso está longe de circular na sociedade capitalista, na qual a educação está voltada, de maneira alienante, para as demandas do mercado. um conjunto de reformas que alteraram expressivamente a estrutura do Estado brasileiro e suas funções, em especial em relação à educação.

De acordo com Castanho (2003) as medidas pontuais do ajuste neoliberal promovido por FHC consistiram: na Reforma do Estado com vistas à redução dos deveres do Poder Público, transferindoos para a iniciativa privada; criação do Plano Real objetivando o ajuste monetário; relações de trabalho mais flexíveis; Reforma da Previdência; Reforma Educacional, essencialmente com aprovação da LDB e outras medidas legais e administrativas; ajuste fiscal; controle do déficit público, tais quais as exigências do FMI.

A Lei de Diretrizes e Bases da Educação LDB (Lei 9.394/96), aprovada em 1996, depois de um longo e tortuoso processo, foi um importante passo do então governo para reforma educativa brasileira.

Em tramitação no Congresso Nacional desde a promulgação da Constituição de 1988, o primeiro texto da LDB proposto para votação foi resultado de um amplo debate que envolveu diversas entidades vinculadas à educação, congregadas no Fórum Nacional em Defesa da Escola Pública. Entretanto, o pensamento dos educadores progressistas e sua proposta não eram compatíveis com a ideologia e com as políticas de ajuste neoliberal e, por isso, foi duramente combatido e rejeitado pelo governo. Aprovou-se então um texto adequado aos interesses dominantes dentro do contexto educacional proposto para atender as necessidades do mercado capitalista. Um projeto coerente com a proposta de desregulamentação, descentralização e de privatização e compatível com o Estado Mínimo para as políticas sociais, adotado pelo governo FHC.

A implementação da LDB pode ser caracterizada, portanto, como parte de um conjunto 
das medidas institucionais que mostram a afinidade político-ideológica entre o governo federal e as agências internacionais, na adoção de uma proposta educacional inspirada também no pensamento pedagógico empresarial.

Segundo Saviani a concepção neoliberal foi predominante em todas as iniciativas de política educacional deste governo, que se empenhou em "reduzir custos, encargos e investimentos públicos buscando senão transferi-los, ao menos dividi-los (parceria é a palavra da moda) com a iniciativa privada e as organizações governamentais" (SAVIANI, 2000, p. 200-201).

Em análise ao octênio do governo FHC, Sguissardi (2006) elenca alguns aspectos importantes adquiridos pela educação superior brasileira nesse período, dentre os quais é importante destacarmos: a baixa cobertura do sistema; a diversidade institucional; a privatização do sistema, predominância do setor privado em relação ao público, com um crescimento de $118 \%$ das Instituições de Ensino Superior (IES) privadas e aumento de $70 \%$ nas matrículas; distorção da distribuição regional da educação superior; má distribuição por área de conhecimento, concentrando no setor privado áreas que exigem baixos investimentos, mas com altos retornos financeiros; redução de $33 \%$ do PIB para o financiamento das Instituições Federais de Ensino Superior (IFES); expansão de um modelo de universidade de ensino em detrimento de universidade de pesquisa; legislação educacional voltada, sob muitos aspectos, para as teses e orientações dos organismos multilaterais, garantindo a grande expansão do setor privado; aprovação do Plano Nacional de Educação (PNE), em que se vetaram as principais metas relativas à educação superior, enfatizando a desresponsabilização do Estado com a educação.
$\mathrm{Na}$ concepção de Sguissardi (2006) houve uma mudança dos modelos clássicos de universidades para os "modelos de ocasião", orientados nas diretrizes do Banco Mundial.

Atrelado a isso, houve nesse período um fortalecimento do empresariamento da educação superior através do aumento das IES privadas. No decorrer dos oito anos do governo FHC (1995-2002) o número de IES praticamente dobra, de 894 para 1.637, sendo que este aumento se deve em grande parte às IES privadas, que já eram em maior número. O percentual, que em 1995 era de 23,5\% públicas e $76,5 \%$ privadas, passa para $11,9 \%$ públicas e $88,1 \%$ privadas, em 2002 (MEC/INEP, 2002).

No início do mandato de FHC, em 1995, segundo os dados das Sinopses Estatísticas do Censo da Educação Superior (MEC/INEP), tínhamos o total de matrícula de graduação presencial de 1.759.703, das quais 700.540 matrículas eram da rede pública $(39,8 \%)$ e 1.059 .163 eram matrículas da rede privada $(60,2 \%)$. Ao final do seu mandato, em 2002, atingimos o total de 3.479.913 matrículas, das quais 1.051.655 (30,2\%) na rede pública e 2.428.258 $(69,8 \%)$ na rede privada.

A privatização interna das universidades públicas, por meio da diversificação das fontes de financiamento, também consistiu um importante mecanismo no processo de empresariamento da educação superior. Por meio do qual as universidades públicas, em especial as federais, passaram por um profundo reordenamento jurídico:

\footnotetext{
${ }^{3}$ Sguissardi (2006, p. 1024) usa o termo "modelos de ocasião", para destacar que a universidade brasileira está sendo conduzida a transitar dos modelos clássicos para o modelo de "universidade mundial do Banco Mundial", fundado nas teses neo ou ultraliberais da economia e do Estado.
} 
[...] a venda de "serviços educacionais", como os cursos pagos, especialmente os cursos de pósgraduação lato sensu; o estabelecimento de parcerias entre as universidades federais e as empresas para realização de consultorias e assessorias viabilizadas pelas fundações de direito privado; a concepção de política de extensão universitária como venda de cursos de curta duração; a criação de mestrados profissionalizantes, em parcerias com empresas públicas e privadas, considerados como cursos autofinanciáveis, isto é, cursos pagos, entre outros mecanismos internos de privatização (LIMA, 2011, p. 90).

Portanto, existe uma convergência entre as políticas implementadas pelo governo FHC teses neoliberais tuteladas pelo Banco Mundial nos seus documentos pontuais, dando curso a um intenso processo de reforma do Estado capitalista e da educação superior do Brasil.

\section{EXPANSÃO DO SETOR PRIVADO E PRIVATIZAÇÃO DAS INSTITUIÇÕES PÚBLICAS: O LEGADO DE LULA}

Embora tenha gerado expectativas positivas, considerando sua trajetória sindicalista, o governo Lula (2003-2010) avançou no caminho estabelecido pelos governos Collor, Itamar e FHC, ambos alinhados ao Banco Mundial, conforme vimos, aprofundando o processo de reformulação da educação superior, por meio de um conjunto de leis, decretos e medidas que intensificaram a política de diversificação das instituições de ensino superior, assim como também das fontes de financiamento para este nível.

A Lei de Inovação Tecnológica, aprovada em 2004, estabeleceu a parceria entre universidades públicas e empresas, sob o argumento de incentivo à inovação e à pesquisa científica e tecnológica no setor produtivo, estimulando a privatização e aprofundando o empresariamento da educação e da ciência e tecnologia dentro das instituições públicas.
Para Sguissardi (2006) esta lei colocou em risco a função pública da universidade no campo científico e de inovação, subordinando-a ao campo empresarial. Limitando a liberdade acadêmica e, segundo o autor, aprofundando o fenômeno da "heteronomia universitária", em que a universidade obedece cada vez mais estritamente aos interesses mercadológicos.

Com o Projeto de Parceria Público-Privada PPP (2004), abrangendo uma série de atividades do governo, prevê-se a parceria do Estado com as empresas privadas em diferentes áreas. No âmbito educacional, houve uma ampliação na utilização de recursos públicos por entidades privadas.

A implementação de parcerias públicoprivadas na educação superior foi expressa também na criação do Programa Universidade para Todos PROUNI, lançado oficialmente em 2004, em que se amplia a isenção fiscal para as IES privadas em troca de vagas públicas nas mesmas, fortalecendo o comércio de instituições privadas de ensino e ocupando um lugar central na reforma da educação superior.

O PROUNI é permeado por vários aspectos privatizantes no âmbito da educação superior brasileira, dentre os quais Mancebo (2004) destaca: a redução dos investimentos nas instituições públicas; diminuição das fronteiras entre o público e o privado, delegando ao setor privado as responsabilidades do governo; redefinição do papel do Estado e a desvalorização da instituição educacional pública; distorção quanto às funções da universidade, reduzida à formação profissional, em detrimento do seu papel social mais amplo; e adequação às diretrizes dos organismos internacionais que estimulam a privatização.

O Programa de Apoio a Planos de Reestruturação e Expansão das Universidades 
Federais - ReUni, de 2007, é uma das políticas centrais implementadas pelo governo Lula, fundamental para esse estudo.

Tendo como objetivo a criação de condições para a ampliação do acesso e permanência na educação superior, o ReUni trouxe uma forma de reestruturação e expansão da educação superior pública federal baseada, de acordo análise de Lima (2011): na aceleração da formação profissional, na intensificação do trabalho docente e na transformação das universidades em instituições de educação terciária, pondo fim à autonomia das mesmas, uma vez condicionadas a aderir ao programa em troca de verbas públicas.

Seguindo a lições do Banco Mundial o ReUni preconiza a expansão do ensino, o que significa a quebra do tripé ensino-pesquisa-extensão, colocando em xeque a qualidade do projeto político-pedagógico da universidade brasileira. O trabalho educativo do professor fica prejudicado, pois fica restrito às atividades de ensino, em detrimento das atividades de pesquisa e extensão.

Nesse processo, observa-se uma forte tendência à intensificação do trabalho docente, enfatizada no referido programa e tratada eufemisticamente como otimização de recursos humanos.

A expansão da oferta de ensino superior proposta pelo ReUni sela a lógica produtivista e empresarial que perpassa a reforma da educação superior e afeta profundamente a função docente. Cria-se um banco de professores-equivalentes e viabiliza-se a contratação de substitutos, que, segundo Léda e Mancebo (2009, p.59) constituem-se "um mecanismo ágil que força um aumento de produtividade institucional, em detrimento da qualidade, necessariamente, resultando na precarização das condições de trabalho".
A tendência privatizante do governo FHC é aprofundada no contexto do governo de Lula da Silva. Em 2003, as matrículas de graduação presencial no Brasil totalizaram 3.887.022, sendo 1.136.370 (29,23\%) públicas e 2.750.652 (70,77\%) privadas. Em 2010, alcançamos o total de 5.449.120 matrículas, delas 1.461.696 são públicas $(26,82 \%)$, e 3.987.424, representando $73,18 \%$ das matrículas na rede privada (MEC/INEP).

Em 2012, os dados das Sinopses da Educação Superior (MEC/INEP) mostram que do total de 2.416 instituições de ensino superior, apenas 304 são públicas e as outras 2.112 são privadas. Permaneceu o processo de diversificação das instituições de ensino superior, com 193 universidades (8\%), 139 centros universitários $(5,8 \%), 2.044$ faculdades isoladas $(84,6 \%), 40$ IFs e Cefets $(1,7 \%)$. Das 7.037.688 matriculas na graduação 1.897.376 foram realizadas na rede pública $(27 \%)$ e 5.140 .312 foram realizadas na rede privada $(73 \%)$.

Os dados apresentados evidenciam o estímulo à privatização da educação superior no governo Lula, tanto na privatização interna das instituições públicas como na ampliação das privadas, permanecendo a lógica mercantil do governo anterior.

\section{CONSIDERAÇÕES FINAIS}

As políticas implementadas nos governos estudados consolidaram uma intensa reforma no cenário educacional brasileiro, no qual a educação passou a ser enfatizada como fator essencial para o desenvolvimento do mundo produtivo, acompanhada por um conjunto de discursos, ideias e propostas que definiram a forma neoliberal de pensar e delinear a educação, a partir do seu programa de estabilização e reforma econômica.

A intervenção protagonizada pelo Banco Mundial nos países periféricos ao longo dos anos, 
dentro do projeto hegemônico capitalista, fez da instituição um instrumento fundamental na implementação de políticas estratégicas à manutenção e expansão mundializada do capital.

As políticas aqui incorporadas visam atender aos interesses do capital e são sim decorrentes de um processo de intervenção internacional, mas os governos brasileiros e as elites nacionais partilham de tais interesses.

A concepção de educação defendida por FHC esteve pautada no projeto neoliberal de empregabilidade, para a inserção dos indivíduos no mercado de trabalho, garantindo a adequação do Brasil ao mundo capitalista. O governo Lula não só manteve os pilares do modelo capitalista neoliberal, como aprofundou a mercantilização da educação superior, conforme dados apresentados.

Sob o manto de democratização do acesso, o conjunto de leis, medidas e decretos desses governos, reordenou política e juridicamente a educação superior brasileira, consolidando um intenso processo de privatização e empresariamento deste nível de ensino, por meio da diversificação das instituições de ensino superior, dos cursos e das fontes de financiamento, de acordo com as diretrizes dos organismos internacionais, e de responsabilização do Estado, via redução das verbas para o setor público.

Portanto, numa sociedade em que o mercado é que toma as decisões, a educação superior, no conjunto das políticas estratégicas, é pensada e delineada para atender a interesses estritamente econômicos. O Banco Mundial, como agência de financiamento, utiliza-se do seu poder políticoideológico para formulação e implementação de reformas educacionais vinculadas aos interesses e necessidades do mercado de trabalho, restringindo a educação ao papel de reprodutora de força de trabalho e de (con) formadora das relações sociais capitalistas, tornando-se um lucrativo setor do mercado a ser explorado pela iniciativa privada.

A educação superior pública vem sendo atacada pelo neoliberalismo por meio de uma série de estratégias privatizantes, mediante a aplicação de uma política de descentralização e de reforma que, em termos reais, procura inviabilizar a possibilidade de uma educação verdadeiramente democrática, pública e de qualidade para todos.

Todos os autores declararam não haver qualquer potencial conflito de interesses referente a este artigo.

\section{REFERÊNCIAS}

BANCO MUNDIAL. Educação Superior: lições derivadas da experiência. Washington, 1994. Disponível em: http://www.bancomundial.org.br. Acesso em: 15 set. 2013.

Relatório sobre o desenvolvimento mundial. O Estado em um mundo em transformação. 1997. Disponível em: http://www.bancomundial.org.br/index.php/content/v iew_folder/94.html. Acesso em: 16 set. 2013.

\section{Documento estratégico do Banco} Mundial. A educação na América Latina e Caribe. $1999 . \quad$ Disponível em: <http://www.bancomundial.org.br>. Acesso em: 08 abr. 2010 .

Construir sociedades de conhecimento: novos desafios para a educação terciária. 2002. Disponível em: http://siteresources.worldbank.org/EDUCATION/ Resources/278200-1099079877269/5476641099079956815/CKS-spanish.pdf. Acesso em: 18 set. 2013

BRASIL. INEP - Instituto Nacional de Estudos e Pesquisas Educacionais. Censo da Educação Superior Brasileira.Resumo Técnico, 2002. Disponível em: http://www.inep.gov.br/download/superior/censo/tabe las_resumo_tec_.xls. Acesso em: 05 out. 2013.

Censo da Educação Superior Brasileira. Sinopse Educação Superior, 2012. Disponível em: http://portal.inep.gov.br/superior-censosuperiorsinopse. Acesso em: 10 nov. 2013. 
BRASIL, Ministério da Educação. Plano Nacional de Educação para todos: 1993-2003. Brasília: MEC, 1993.

BRASIL. Lei no 9.394, de 20 de dezembro de 1996. Estabelece as diretrizes e bases da educação nacional. Diário Oficial da União, Brasília, DF, 23 dez. 1996. Disponível em: http://www.planalto.gov.br/ccivil_03/leis/19394.htm. Acesso em: 19 out. 2013.

Lei no 10.973, de 2 de dezembro de 2004. Dispõe sobre incentivos à inovação e à pesquisa científica e tecnológica no ambiente produtivo e dá outras providências. Diário Oficial da União, Brasília, DF, 3 dez. 2004a. Disponível em: http://www.planalto.gov.br/ccivil_03/_ato2004-

2006/2004/lei/110.973.htm. Acesso em: 15 out. 2013.

Medida Provisória $\mathrm{n}^{\mathrm{o}}$ 213, de 10 de Setembro de 2004. Institui o Programa Universidade para Todos - PROUNI, regula a atuação de entidades beneficentes de assistência social no ensino superior, e dá outras providências. Diário Oficial da União, Brasília, DF, 11 set.2004b. Disponível em: http://www.planalto.gov.br/ccivil_03/_ato20042006/2004/Mpv/213.htm. Acesso em: 15 out. 2013.

Projeto de lei no 3.627, 28 abr. de 2004. Institui Sistema Especial de Reserva de Vagas para estudantes egressos de escolas públicas, em especial negros e indígenas, nas instituições públicas federais de educação superior e dá outras providências. Diário Oficial da União, Brasília, DF, 29 abr. 2004c. Disponível em: http://www.presidencia.gov.br/ccivil_03/Projetos/PL/ 2004/msg233-040513.htm. Acesso em: 19 out. 2013.

Lei no 11.079, de 30 de Dezembro de 2004. Institui normas gerais para licitação e contratação de parceria público-privada no âmbito da administração pública. Diário Oficial da União, Brasília, DF, 31 dez.2004d. Disponível em: http://www.planalto.gov.br/ccivil_03/_ato2004-

2006/2004/lei/111079.htm. Acesso em: 19 out. 2013.

Lei no 11.096, de 14 de janeiro de 2005. Institui o Programa Universidade para Todos PROUNI, regula a atuação de entidades beneficentes de assistência social no ensino superior; altera a Lei no 10.891, de 9 de julho de 2005, e dá outras providências.Diário Oficial da União, Brasília, DF, 14 jan. 2005. Disponível em: http://www.planalto.gov.br/ccivil_03/_ato20042006/2005/lei/L11096.htm. Acesso em: 19 out. 2013.
Decreto no 6.096, de 24 de Abril de 2007. Institui o Programa de Apoio a Planos de Reestruturação e Expansão das Universidades Federais -REUNI. Diário Oficial da União, Brasília, DF, 25 abr. 2007. Disponível em: http://www.planalto.gov.br/ccivil_03/_ato2007-

2010/2007/decreto/d6096.htm. Acesso em: 23 out. 2013.

CASTANHO, Sérgio. E. M. Globalização, redefinição do Estado nacional e seus impactos. In: José Claudinei Lombardi. (Org.). Globalização, PósModernidade e Educação. 2 ed. Campinas: Autores Associados, 2003, v. 1, p. 13-38.

LÉDA, Denise B. \& MANCEBO, Daise. REUNI: heteronomia e precarização da universidade e do trabalho docente. Revista Educação \& Realidade, Porto Alegre, v. 34, n. 1, 49-64, jan/abr. 2009. Disponível em: http://seer.ufrgs.br/index.php/educacaoerealidade/arti cle/view/ 8457/4922. Acesso em: 22 set. 2013.

LIMA, Kátia. O Banco Mundial e a educação superior brasileira na primeira década do novo século. Revista Katál. Florianópolis. v. 14, n.1, 8694, jan/jun. 2011. Disponível em: http://www.scielo.br/pdf/rk/v14n1/v14n1a10.pdf. Acesso em: 20 ago. 2013.

MANCEBO, Daise. Reforma universitária: reflexões sobre a privatização e a mercantilização do conhecimento. 2004. Disponível em: http://www.scielo.br/pdf/es/v25n88/a10v2588.pdf.

Acesso em: 07 out. 2013.

MARTINS, Lígia Márcia. Da formação humana em Marx à crítica da pedagogia das competências. In: DUARTE, Newton (org.). Crítica ao fetichismo da individualidade. Campinas, SP: Autores Associados, 2004, p. 53-73.

SAVIANI, Dermeval. Concepções de desenvolvimento e de educação e o papel do estado no Brasil hoje: um balanço crítico. In: SEMINÁRIO DESENVOLVIMENTO E EDUCAÇÃO: QUAL DESENVOLVIMENTO E EDUCAÇÃO PARA QUAL SOCIEDADE? Rio de Janeiro, UERJ, 18 de novembro de 2010. Disponível em: http://www.uerj.br/lendo_noticia.php?id=162. Acesso em: 20 nov. 2013.

SAVIANI, Dermeval. A nova lei da educação: trajetória e perspectivas. $6^{\mathrm{a}}$ ed. Campinas, SP: Autores Associados, 2000. 
SGUISSARDI, Valdemar. Reforma Universitária no Brasil - 1995-2006: precária trajetória e incerto futuro. Revista Educação \& Sociedade, Campinas, v.27, n.96, 1021-1056, out. 2006. Disponível em: http://www.cedes.unicamp.br. Acesso em: 20 set. 2013.

SILVA, Maria Abádia. Intervenção e consentimento: a política educacional do Banco
Mundial. Campinas, SP: Autores Associados. São Paulo: FAPESP, 2002.

SOARES, M. C. C. Banco Mundial: políticas e reformas. In: DE TOMMASI, L.; WARDE, M. J.; HADDAD, S. (orgs.).O Banco Mundial e as políticas educacionais. São Paulo: Cortez; PUC-SP; Ação Educativa, 1996. p. 15-40. 